\title{
Envelhecimento e cuidados de longa duração
}

\author{
Vicente Paulo Alves*, Paula Regina de Oliveira Ribeiro**
}

\section{Resumo}

O estudo sobre os cuidados de longa duração para idosos no Brasil começou recentemente e tem avançado de forma significativa em diversas produções científicas, principalmente na reivindicação de elaboração de políticas públicas consistentes, que venham atender as demandas por um atendimento digno e humano. Esta reflexão analisa justamente as modalidades de serviços de cuidados de longa duração para idosos previstos na legislação como uma política pública urgente, dado o crescente contingente de idosos, e, ainda, avalia de que maneira esses serviços podem ser implementados no Brasil.

Palavras-chave: Envelhecimento humano. Cuidados de longa duração. Recursos humanos. Políticas públicas.

\section{Introdução}

Apesar de o Brasil ter sido considerado, nas últimas quatro décadas, como um país de jovens, a partir da década de 1980, a situação mudou, de forma que a população idosa começou a ser o grupo que apresenta as taxas mais elevadas de crescimento, resultado da diminuição da taxa de natalidade, do avanço da medicina e dos novos fármacos, que trouxe o consequente aumento contínuo da expectativa de vida.

O número de brasileiros com idade igual ou superior a 60 anos já representa, segundo o Instituto Brasileiro de Geografia e Estatística (IBGE) (2011), aproximadamente $11 \%$ da população total, correspondente a mais de $21 \mathrm{mi}$ lhões de pessoas idosas. As estimativas mostram que seremos o sexto país mais envelhecido do mundo, com uma proporção de um idoso para cada quatro jovens, o que exigirá que as políticas públicas passem a contemplar esse contingente tão grande nas próximas décadas, principalmente quando se fala em cuidados de longa duração.

* Doutor em Ciências da Religião pela Umesp. Professor e coordenador do Programa de Pós-Graduação Stricto Sensu em Gerontologia na Universidade Católica de Brasília. E-mail: vicente@ucb.br

** Graduada em Direito. Especialista em Gerontologia e Saúde do Idoso. Coordenadora do Núcleo de Defesa do Idoso e da Central Judicial do Idoso do Distrito Federal. Mestranda em Gerontologia pela Universidade Católica de Brasília.

$\rightarrow$ http://dx.doi.org/10.5335/rbceh.v12i3.6002

Recebido em: 03/11/2015. Aceito em: 03/11/2015. 
Embora tenhamos esses números impressionantes, o envelhecimento populacional não se reduz apenas à quantidade de velhos existentes. Não se trata de uma questão numérica, mas especialmente de uma questão social relevante e da defesa do direito humano fundamental, que envolve o envelhecimento em diversos aspectos.

Quando conhecemos o perfil sociodemográfico de uma população, torna-se possível formular e implementar políticas públicas em sintonia com as necessidades dos distintos grupos sociais. Assim, para se planejar estratégias políticas conectadas à realidade social apresentada nesses perfis, é preciso criar serviços e atendimentos especializados conforme as demandas apresentadas pelos diversos segmentos populacionais. Entre esses serviços está, sem dúvida, o de cuidados de longa duração.

Notadamente, no que tange à população idosa, considerando o substancial aumento da expectativa de vida e as comorbidades, dependências e limitações decorrentes dessa longevidade, os cuidados de longa duração figuram como uma política pública premente.

Como cuidados de longa duração deve-se considerar uma gama de serviços prestados de forma continuada que visam atender ao idoso em suas necessidades de moradia, alimentação, saúde, convivência familiar e comunitária, garantindo, assim, um envelhecimento com dignidade. No Brasil, as políticas de cuidados de longa duração ainda não são claramente definidas e sua execução situa-se na política de assistência social.
Todavia, apesar dessa alocação dos cuidados de longa duração apenas na assistência, a Organização Mundial de Saúde (OMS) (2008) defende que esses cuidados devam situar-se na interseção entre as políticas de saúde e assistenciais, pois, além de apresentarem algumas peculiaridades próprias a cada uma das áreas, são sutis as diferenciações existentes entre o curar e o cuidar.

No Brasil, os serviços de cuidados de longa duração encontram-se previstos na Lei $\mathrm{n}^{\circ}$ 8.842, de 4 de janeiro de 1994, denominada Política Nacional do Idoso (PNI) (BRASIL, 1994), em que se pode verificar, em seu art. 10, I, b, que compete à área de promoção e assistência social estimular a criação de incentivos e de alternativas de atendimento ao idoso, como centros de convivência, centros de cuidados diurnos, casas-lares, oficinas abrigadas de trabalho, atendimentos domiciliares, dentre outros. O Decreto $\mathrm{n}^{\circ}$ 1.948 , de 3 de julho de 1996, que regulamenta a Política Nacional do Idoso, classifica as modalidades de atendimento como asilares e não asilares e conceitua cada um dos serviços descritos na referida política (BRASIL, 1996).

Não obstante, dentre as diversas modalidades de serviços de atenção ao idoso, no Brasil, difundiu-se apenas o atendimento asilar. As Instituições de Longa Permanência para Idosos (Ilpis) figuram hoje, praticamente, como a única alternativa para aqueles idosos que se encontram sem vínculos familiares, para os que estão fragilizados ou em situação de vulnerabilidade. Então: ou o idoso fica com a família (quando a tem) ou é abrigado em uma Ilpi. 
Esta reflexão pretende analisar justamente as modalidades de serviços de cuidados de longa duração para idosos previstos na legislação como uma política pública urgente, dado o crescente contingente de idosos, e a maneira como esses serviços podem ser implementados no Brasil.

Iniciaremos essa temática, observando o perfil sociodemográfico da população idosa brasileira e a demanda por políticas públicas de cuidados de baixa, média e alta complexidade, bem como modalidades de atendimento que permitam ao idoso e à sua família exercerem o direito de escolha, visando, primordialmente, um envelhecimento digno.

Em seguida, discutiremos que não basta haver uma legislação que responsabilize as famílias pelo cuidado dos seus membros dependentes, mas que o Estado deve se comprometer também com esse processo, não só subsidiando as Ilpis já existentes, que foram fundadas pela iniciativa privada, mas também incentivando a criação de outras modalidades e serviços previstos em leis, que possam ser alternativas para as famílias e os idosos. Assim, o crescimento populacional significativo dos idosos não será visto como uma punição a quem conseguir alcançar longevidade, mas, sim, a comemoração da vitória de políticas públicas que se efetivam em novas modalidades de serviços e cuidados, que despertam maior esperança na qualidade de vida para quem muito contribuiu com o país pelo trabalho e pelo exercício da cidadania. A família, o Estado e a iniciativa privada podem se unir para oferecer dignidade aos seus entes queridos, focando no cuidado de um ambiente humano e acolhedor.

Finalmente, no terceiro tópico, veremos vários serviços de atenção asilar e não asilar prestados aos idosos, demonstrando que há previsão legal de diversas modalidades de atendimento, cabendo ao Estado implementá-las. O papel de protagonista é, portanto, do Estado, que precisa assumir, mais do que discursos ou exigências burocráticas, a forma de viabilizar $o$ atendimento e a assistência aos idosos, no apoio fundamental ao cuidado prestado aos idosos pelas famílias.

\section{0 envelhecimento no Brasil: um panorama dos dados do Censo 2010, da PNAD 2012 e da Síntese dos Indicadores Sociais de 2013}

As mudanças na estrutura etária do Brasil foram substantivas ao longo do tempo, podendo ser observadas tanto na base como no topo da pirâmide etária. Ao observarmos as três pirâmides etárias relativas do Brasil para os anos 1991, 2000 e 2010 , verifica-se um acentuado estreitamento da base, ao mesmo tempo em que o ápice se torna cada vez mais largo, decorrente do contínuo declínio dos níveis de fecundidade e da queda da mortalidade no período (IBGE, 2011). 
Gráfico 1 - Composição da população residente total, por sexo e grupos de idade, Brasil - 1991/2010

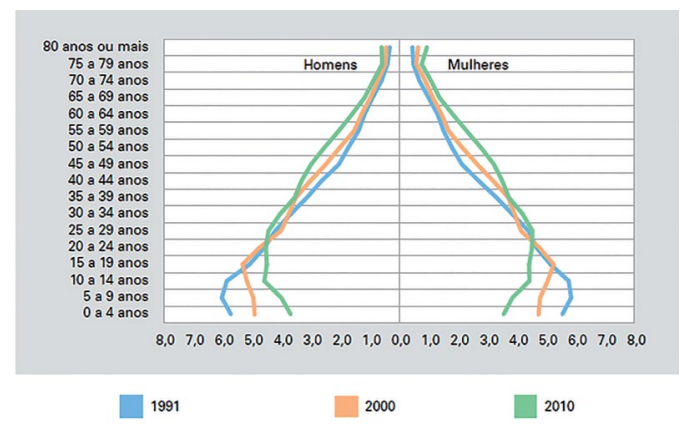

Fonte: IBGE. Censo demográfico 1991/2010.

A representatividade dos grupos etários no total da população em 2010 é menor que a observada em 2000 para todas as faixas com idade até 25 anos, ao passo que os demais grupos etários aumentaram suas participações na última década. $\mathrm{O}$ alargamento do topo da pirâmide, por exemplo, pode ser observado pelo crescimento da participação relativa da população com 65 anos ou mais, que era de $4,8 \%$ em 1991, passando a $5,9 \%$ em 2000 e chegando a 7,4\% em 2010 (IBGE, 2011).

A evolução da estrutura etária observada nas pirâmides nos sugere também que, confirmadas as tendências esperadas de mortalidade e fecundidade, a população do Brasil tende a dar continuidade a esse processo de envelhecimento.

A tendência de envelhecimento populacional fica ainda mais clara ao se considerar a projeção de população realizada pelo IBGE. O segmento de jovens de 0 a 14 anos de idade diminui gradualmente, e atingirá $13 \%$ da população brasileira em 2060. Para o grupo de idosos de 60 anos ou mais de idade, o aumento na participação relativa é acentuado, passando de $13,8 \%$, em 2020, para $33,7 \%$, em 2060, ou seja, um aumento de vinte pontos percentuais. O grupo de idosos de 60 anos ou mais de idade será maior que o grupo de crianças com até 14 anos de idade após 2030, e em 2055 a participação de idosos na população total será maior que a de crianças e jovens com até 29 anos de idade (IBGE, 2013b).

\section{Gráfico 2 - Distribuição percentual da popula- ção projetada por grupos de idade, Brasil - 2020/2060}

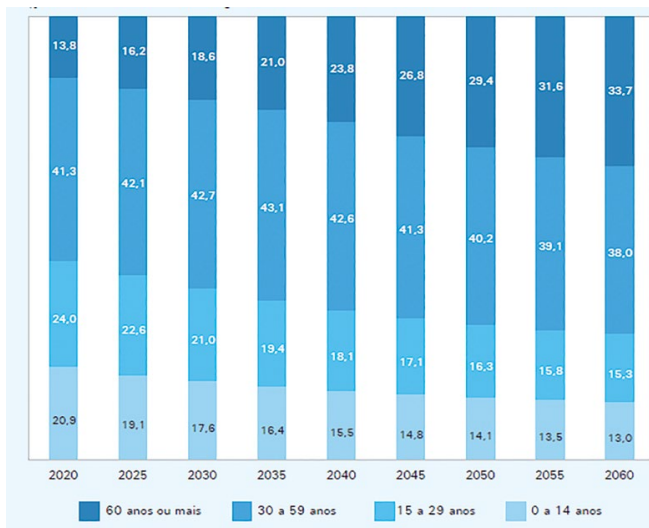

Fonte: IBGE. Projeção da população do Brasil por sexo e idade para o período 2000/2060, revisão 2013; Projeção da população das unidades da federação por sexo e idade para o período 2000/2030, revisão 2013.

Em 2012, a participação relativa dos idosos de 60 anos ou mais de idade foi de $12,6 \%$ da população total. As particularidades mais marcantes para os idosos de 60 anos ou mais são: maioria feminina $(55,7 \%)$ e branca $(54,5 \%)$; presença de 84,3\% em áreas urbanas; inserção no domicílio como a pessoa de referência $(64,2 \%)$, especialmente no caso dos homens (80,5\%); média de 4,2 anos de estudo, sendo que $28,1 \%$ tinham menos de 
1 ano de estudo e somente $7,2 \%$ tinham graduação completa ou mais; grande maioria $(76,3 \%)$ recebia algum benefício da previdência social, sendo que $76,2 \%$ dos homens e $59,4 \%$ das mulheres eram aposentados; $47,8 \%$ tinham rendimento de todas as fontes superior a um salário mínimo, mas $43,5 \%$ residiam em domicílios com rendimento mensal per capita igual ou inferior a um salário mínimo (IBGE, 2013a).

Gráfico 3 - Distribuição percentual das pessoas de 60 anos de idade ou mais, segundo sexo, cor ou raça, situação do domicílio e condição do domicílio, Brasil - 2012

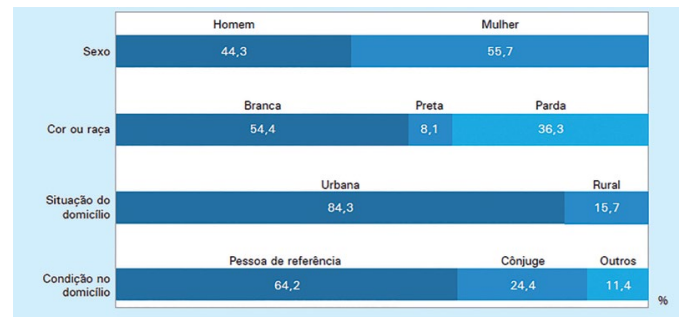

Fonte: IBGE. Pesquisa Nacional por Amostra de Domicílios 2012.

Gráfico 4 - Distribuição percentual das pessoas de 60 anos de idade ou mais, segundo os anos de estudo, a previdência, o rendimento mensal de todas as fontes e o rendimento mensal domiciliar per capita, Brasil - 2012

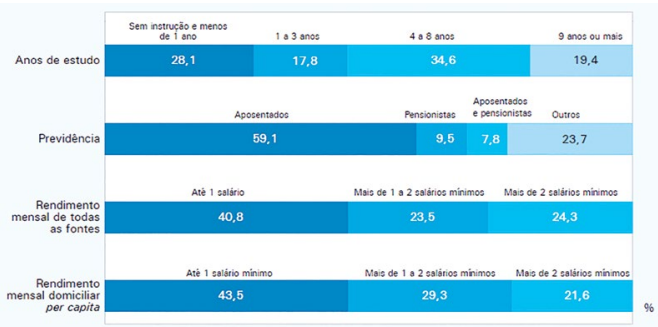

Fonte: IBGE. Pesquisa nacional por amostra de domicílios 2012.
Uma questão relevante ao tratar desse público se refere ao tipo de arranjo domiciliar no qual o idoso está inserido. Cerca de um em cada quatro idosos vivia em arranjo formado por casal sem filhos, outros parentes ou agregados. Outro arranjo comum $(30,2 \%)$ foi aquele em que o idoso vivia com os filhos, sendo todos os filhos com 25 anos de idade ou mais. Ainda, 14,8\% dos idosos viviam em domicílios unipessoais. Dessa forma, $85,2 \%$ dos idosos estavam em arranjos em que havia presença de outra pessoa com quem estabelecesse alguma relação familiar, cônjuge, filho, parente ou agregado (IBGE, 2013a).

\section{Cuidados de longa duração para idosos}

Como já destacado, o envelhecimento da população brasileira apresenta características próprias e se destaca pela longevidade da população idosa. Desde os anos 1970, o país experimenta uma queda acentuada nos níveis de fecundidade e de mortalidade de sua população, bem como mudanças na configuração dos arranjos familiares (INSTITUTO DE PESQUISA ECONÔMICA APLICADA, 2011). Essas mudanças, associadas a outros fatores, como renda, empregabilidade, presença da mulher no mercado de trabalho, podem enfraquecer os laços de solidariedade intergeracionais e comprometer a atuação das famílias enquanto promotoras de apoio e cuidados à população idosa (CAMARANO, 2004, 2005, 2010).

Embora seja possível desfrutar de boa qualidade de vida até idades avançadas, o fato é que a população idosa é mais 
predisposta a apresentar dependência física, déficits cognitivos e dificuldades associadas ao autocuidado e à manutenção de uma vida independente (BALTES; SMITH, 2006).

A legislação brasileira reserva às famílias a responsabilidade pelo cuidado dos membros dependentes, mas isso está se tornando cada vez mais difícil, devido à redução da fecundidade, às mudanças no casamento e ao papel de cuidadora que a mulher vem assumindo na sociedade atual (CAMARANO; KANSO, 2010). Assim, sobra para o Estado bem como para a iniciativa privada dividir com a família essa responsabilidade em acolher as pessoas idosas. Infelizmente, a prática do abrigamento em Ilpis é recorrente no Brasil, e não é a melhor opção para dar dignidade e qualidade de vida a idosos, pois há outras modalidades preconizadas na legislação que podem atender situações de idosos independentes ou semidependentes.

No passado, as instituições religiosas, de diferentes confissões, tomaram a iniciativa diante do descaso do Estado e implementaram diversas Ilpis pelo país, mas, com a legislação cada vez mais rigorosa e com menor número de voluntários, o número de Ilpis mantidas por entidades religiosas tem diminuído significativamente. Segundo Camarano e Kanso, "[...] no Brasil, não há consenso sobre o que seja uma ILPI. Sua origem está ligada aos asilos, inicialmente dirigidos à população carente que necessitava de abrigo, frutos da caridade cristã diante da ausência de políticas públicas" (2010, p. 233).
Isso leva à indagação de quem oferecerá, em um futuro imediato, os cuidados para os idosos: a família ou as instituições privadas e/ou os serviços públicos especializados? Ou, ainda, será possível conjugar as duas formas de cuidados, isto é, manter o idoso na família e implantar serviços de suporte nos cuidados ao idoso?

Em face desse panorama, torna-se urgente pensar em modalidades de cuidados de longa duração alternativos, os quais possam responder às necessidades sociais e de saúde associadas ao envelhecimento, amparando as famílias e os idosos.

Os cuidados de longa duração compreendem uma variedade de serviços médicos, sociais e de atenção pessoal com o objetivo de auxiliar os idosos a viverem da forma mais independente e autônoma possível (FERRINI; FERRINI, 2008), bem como oferecer apoio às famílias e aos idosos situados em diferentes graus de dependência e vulnerabilidade social. Por isso, defendemos a atuação do Estado em elaborar e definir políticas públicas para o setor, mais do que gerenciar instituições, uma vez que a experiência tem demonstrado a sua incapacidade de gestão, e que essa tem sido uma das maiores fontes de desvio de verba pública e corrupção. 
Legislação sobre os diferentes tipos de cuidado e serviços que podem ser prestados aos idosos (na modalidade asilar ou não asilar)

A Constituição Federal de 1988 prevê, em seu art. 230 que é dever da família, da sociedade e do Estado amparar as pessoas idosas, assegurando sua participação na comunidade, defendendo sua dignidade e bem-estar e garantindo-lhes o direito à vida. Estabelece, ainda, que os programas de amparo ao idoso serão executados, preferencialmente, no âmbito do seu domicílio (RAMOS, 2002).

Esse princípio da solidariedade familiar também está expresso na Lei $\mathrm{n}^{\mathrm{o}}$ 8.842, de 1994, a Política Nacional do Idoso, associado à previsão de uma série de serviços de cuidados de longa duração, seja na modalidade asilar ou não asilar.

A Política Nacional do Idoso prevê, em seu art. $4^{\circ}$, III, como uma de suas diretrizes, a priorização do atendimento ao idoso por meio de suas próprias famílias, em detrimento do atendimento asilar, exceto idosos que não possuam condições de garantir a sua própria subsistência. E prossegue dispondo que compete à área da assistência social estimular a criação de alternativas de atendimento ao idoso, como centros de convivência, centros de cuidados diurnos, casas-lares, oficinas abrigadas de trabalho, atendimentos domiciliares, etc. (SOUSA, 2011).

O Decreto no 1.948 , de 1996, que regulamenta a PNI, classifica as modalidades de atendimento ao idoso como asilares e não asilares. Por modalidade asilar, entende-se $o$ atendimento pres- tado em regime de internato, ao idoso sem vínculo familiar ou sem condições de prover a própria subsistência de modo a satisfazer as suas necessidades de moradia, alimentação, saúde e convivência social. Por modalidade não asilar tem-se:

a) centro de convivência: local destinado à permanência diurna do idoso, onde são desenvolvidas atividades físicas, laborativas, recreativas, culturais, associativas e de educação para a cidadania;

b) centro de cuidados diurno (hospital-dia e centro-dia): local destinado à permanência diurna do idoso dependente ou com deficiência temporária, que necessite de assistência médica ou de assistência multiprofissional;

c)casa-lar: residência, em sistema participativo, cedida por instituições públicas ou privadas, destinada a idosos detentores de renda insuficiente para sua manutenção e sem família;

d) oficina abrigada de trabalho: local destinado ao desenvolvimento, pelo idoso, de atividades produtivas, proporcionando-lhe oportunidade de elevar sua renda, sendo regida por normas específicas;

e) atendimento domiciliar: serviço prestado ao idoso dependente e que vive só, a fim de suprir as suas necessidades da vida diária. Esse serviço é prestado em seu próprio lar, por profissionais da área de saúde ou por pessoas da própria comunidade.

Em 2001, foi editada a Portaria $\mathrm{n}^{\mathrm{o}}$ 73, do Ministério da Previdência e Assis- 
tência Social (BRASIL, 2001), mais um instrumento de regulamentação da PNI, que definiu normas e padrões de funcionamento para os serviços e programas de atenção à pessoa idosa, prevendo as seguintes modalidades de atendimento:

a) família natural: atendimento prestado ao idoso independente pela sua própria família, com vistas à manutenção da autonomia, à permanência no próprio domicílio, preservando o vínculo familiar e de vizinhança;

b) família acolhedora: programa que oferece condições para que o idoso sem família, ou impossibilitado de conviver com essa, receba abrigo, atenção e cuidados de uma família cadastrada e capacitada para oferecer esse atendimento;

c) residência temporária: serviço público ou privado, prestado em regime de internação temporária, oferece atendimento ao idoso dependente que requeira cuidados biopsicossociais sistematizados, no período máximo de sessenta dias;

d) república: alternativa de residência para os idosos independentes, organizada em grupo e em sistema de autogestão, conforme o número de usuários, e cofinanciada com recursos de aposentadoria, benefício de prestação continuada, renda mensal vitalícia, dentre outras formas de renda dos próprios idosos;

e) centro de convivência: espaço destinado à frequência de idosos e seus familiares, onde são desenvolvidas, planejadas e sistematizadas ações de atenção ao idoso, de forma a elevar a qualidade de vida, promover a participação, a convivência social, a cidadania e a integração intergeracional;

f) centro dia: espaço destinado a atender idosos com limitações para a realização das atividades da vida diária, que convivem com suas famílias, porém não dispõem de atendimento de tempo integral no domicílio;

g) casa-lar: residência participativa destinada a idosos sem família ou afastados do convívio familiar e com renda insuficiente para sua sobrevivência;

h) assistência domiciliária: prestado à pessoa idosa com algum nível de dependência, com vistas à promoção da autonomia, à permanência no próprio domicílio, ao reforço dos vínculos familiares e de vizinhança;

i) atendimento integral institucional: prestado em uma instituição asilar, prioritariamente a idosos sem família ou em situação de vulnerabilidade, com o oferecimento de serviços que visem suprir todas as suas necessidades básicas.

Com a promulgação da Lei $\mathrm{n}^{0}$ 8.742/1993, denominada Lei Orgânica da Assistência Social e a consequente criação do Sistema Único da Assistência Social, essas modalidades de atendimento foram aperfeiçoadas, consoante prevê a Resolução $\mathrm{n}^{\circ}$ 109, de 11 de novembro de 2009, do Conselho Nacional da Assistência Social, que aprova a Tipificação nacional dos serviços socioassistenciais (BRASIL, 2009). 
O Estatuto do Idoso, Lei no 10.741 , de $1^{\circ}$ de outubro de 2003 , reforça o entendimento das legislações anteriores ao instituir a família como o locus e a principal responsável pelos cuidados com o idoso (BRASIL, 2003). Esse estatuto não classifica ou tipifica as modalidades de atendimento, mas foi o primeiro instrumento normativo a introduzir o termo instituição de longa permanência para idosos, adaptado do Long-Term Care Institution utilizado pela OMS. O documento eleva $o$ atendimento das Ilpis e casas-lares ao status de prestação de serviços, fundadas no direito das relações de consumo, que obriga as instituições, independentemente de sua personalidade jurídica, a firmar contrato de prestação de serviços com a pessoa abrigada ou seu familiar/ curador, no caso de incapacidade, e ter seus programas inscritos no Conselho do Idoso e na Vigilância Sanitária.

\section{Considerações finais}

Frente às projeções de envelhecimento populacional do Brasil para as próximas décadas, o desafio colocado para as políticas públicas nacionais deve compreender um aumento da demanda e da diversidade no fornecimento de serviços que possibilitem uma vida longa e de qualidade, com saúde e dignidade. Não basta apenas apoiar as Ilpis - suprimento de alimentos e pagamento de funcionários; é preciso formação de qualidade para os profissionais que ali atuam, incentivando novas iniciativas nesse modelo de assistência e criando meios para que outras modalidades vistas nesta reflexão possam ser efetivadas.
É preciso buscar estratégias alternativas de atendimento para que haja experiências exitosas em todos os estados e municípios. Isso é o que nomeamos política pública orgânica, estruturada, em que o Estado é protagonista e não se omite diante da realidade dos seus idosos, mas assume como algo que vem subsidiar as famílias no cumprimento de suas obrigações, que é preservar a vida.

\section{Aging and long-term care}

\section{Abstract}

The study on the long-term care for the elderly in Brazil began recently and has advanced significantly in various scientific publications, mainly in the preparation of claim consistent public policies that will meet the demands for a dignified and human care. This reflection is specifically intended to examine how long-term care services for the elderly in the legislation as an urgent public policy, given the increasing number of elderly people, and how these services can be implemented in Brazil.

Keywords: Human aging. Long-term care. Human Resources. Public policy.

\section{Referências}

BALTES, P.; SMITH, J. Novas fronteiras para o futuro do envelhecimento: a velhice bem-sucedida do idoso jovem aos dilemas da quarta idade. A Terceira Idade, São Paulo SP, v. 17, n. 36, p. 7-31, 2006.

BRASIL. Estatuto do Idoso: Lei nº. 10.741, de $1^{\circ}$ de outubro de 2003. Brasília: SDH, 2013.

BRASIL. Política Nacional do Idoso: Lei $\mathrm{n}^{\mathrm{o}}$ 8.842, de 04 de janeiro de 1994. Brasília: Presidência da República, 1995. 
BRASIL. Decreto $n^{\circ} 1.948$, de 3 de julho de 1996. Brasília: Presidência da República, 1996. Disponível em: <http://www.dji.com. br/decretos/1996-001948-htm>. Acesso em: 9 abr. 2014.

BRASIL. Ministério da Previdência e Assistência Social. Portaria n⿳ 73 , de 10 de outubro de 2001. Brasília: MPAS/SEAS, 2001. Disponível em: <http://www.mds.gov.br>. Acesso em: 3 maio 2014 .

BRASIL. Secretaria de Direitos Humanos. Plano de ação internacional para o envelhecimento. Brasília: Presidência da República/ SEDH, 2007.

CONSELHO NACIONAL DE ASSISTÊNCIA SOCIAL. Resolução $n^{\circ} 109$, de 11 de novembro de 2009. Tipificação nacional de serviços socioassistenciais. Brasília: CNAS, 2009.

CAMARANO, A. Os novos idosos brasileiros: muito além dos 60? Rio de Janeiro: Ipea, 2004.

. Idosos brasileiros: indicadores de condições de vida e de acompanhamento de políticas. Brasília: SEDH, 2005.

- Cuidados de longa duração para a população idosa: um novo risco social a ser assumido? Rio de Janeiro: Ipea, 2010.

CAMARANO, A.; KANSO, A. A. As instituições de longa permanência para idosos no Brasil. Revista Brasileira de Estudos de População, Rio de Janeiro, v. 27, n. 1, p. 233235, jan./jun. 2010. Disponível em: <http:// www.scielo.br/pdf/rbepop/v27n1/14.pdf>. Acesso em: 28 jun. 2014.

FERRINI, A.; FERRINI, R. Health in the later years. 4. ed. Boston: The McGraw-Hill Companies, 2008.

IBGE. INSTITUTO BRASILEIRO DE GEOGRAFIA E ESTATÍSTICA. Síntese de indicadores sociais. Uma análise das condições de vida da população brasileira. Rio de Janeiro: IBGE, 2013a. Disponível em: <http://www. ibge.gov.br>. Acesso em: 18 abr. 2014.
. Projeção da população do Brasil por sexo e idade 2000-2060. Projeção da população das Unidades da Federação por sexo e idade 2000-2030. Rio de Janeiro: IBGE, 2013b. Disponível em: <http://www. ibge.gov.br/home/estatistica/populacao/projecao_da_populacao/2013/default_tab.shtm>. Acesso em: 18 abr. 2014.

. Sinopse do censo demográfico 2010. Rio de Janeiro: IBGE, 2011. Disponível em: <http://www.ibge.gov.br>. Acesso em: 18 abr. 2014.

IPEA. INSTITUTO DE PESQUISA ECONÔMICA APLICADA. Condições de funcionamento e infraestrutura das instituições de longa permanência para idosos no Brasil. Infraestrutura social e urbana no Brasil. Subsídios para uma agenda de pesquisa e formulação de políticas públicas. Rio de Janeiro: Ipea, 2011. (Série Eixos do Desenvolvimento Brasileiros, N. 93).

OMS. ORGANIZAÇÃO MUNDIAL DE SAÚDE. Home care in Europe. 2008. Disponível em: <www.euro.who.int>. Acesso em: 18 abr. 2014.

RAMOS, P. Fundamentos constitucionais do direito à velhice. Florianópolis: Obras Jurídicas, 2002.

SOUSA, A. Tutela jurídica do idoso: a assistência e a convivência familiar. 2. ed. Campinas: Alínea, 2011. 